\section{Selective attention to words and colors}

\author{
ANNE D. PICK, HERBERT L. PICK, JR., and JACQUELINE J. HALES* \\ University of Minnesota, Minneapolis, Minn. 55455
}

Ss made same/different judgments for pairs of words that were either color names or object names. The words of a pair were printed in either matching or different color print. Responses were directed either to print color or to the words or to both the print color and the words. Both print color and color names lengthened response time in several experimental conditions. A hypothesis was suggested that only the information necessary for judgments is processed initially; the words are read, and interference is produced only after color and/or letter-shape differences have been detected.

Recently there has been great interest in tasks that require $\mathrm{Ss}$ to respond to one of several stimulus variables simultaneously presented as a method for studying processes of attention (e.g., Egeth, 1967; Egeth, Blecker, \& Kamlet, 1969; Posner \& Mitchell, 1967; Treisman, 1969). Interference by one variable with responses to another variable provide information both about stimulus salience and about the cognitive or perceptual "levels" at which stimulus information is analyzed.

The stimulus variables in this study are similar to those used for the "Stroop" studies. The experimental task required discrimination among pairs of words on the basis of print color, or words, or both print color and words. Changes in reaction time to one of these aspects as a function of variations in the other aspects should suggest how the stimulus information is processed.

The Ss were 27 University of Minnesota undergraduates about equally divided between men and women.

\section{MATERIALS}

Ten pairs of words were used: brown-brown, green-green, brown-green, green-brown, chair-chair, fruit-fruit, chair-fruit, fruit-chair, heart-field, field-heart. The words were printed, in pairs, on $35-\mathrm{mm}$ slides in either green or brown print. Fourteen pairs were used for the experimental procedure: two pairs of object names and two pairs of color names in which the words of the pair and the print color matched; one pair of object names and one pair of color names in which the words of the pair matched but the print color did not; two pairs

*This research was supported by a Program Project grant, No. 5 PO1 HD05027, from the National Institute of Child Health and Human Development to the University of Minnesota and by the Center for Research in Human Learning at the University of Minnesota. The research was conducted while the second author held an NIH career development fellowship. No. 1-K3-HD 12,396. of object names and one pair of color names in which the words of the pair did not match but the print color did; and three pairs of object names and two pairs of color names in which neither the words of the pair nor the print color matched.

\section{APPARATUS AND PROCEDURE}

The slides were presented through a rear projection apparatus. The $\mathrm{S}$ viewed the slides through an aperture that restricted his peripheral vision. $\mathrm{He}$ was seated in front of the apparatus, and his task was explained. He would be shown pairs of words and asked to answer as quickly as possible one of three questions: Are the words the same? Are the colors the same? Are both the words and colors the same? The various possibilities of matching or mismatching of words and colors were explained, and some were demonstrated to ensure that the $\mathbf{S}$ could perceive the colors and the words distinctly.

The $\mathrm{S}$ was informed of the required judgment simultaneously with the presentation of the pair of words. The abbreviations, word, color, both, were used to signal the judgment. The $S$, using the index finger of his preferred hand, responded by pressing one of two buttons ("yes" or "no"), which also removed the slide from view. The response buttons were located side by side on a panel below the viewing aperture. The buttons were separated by 3 in., and the $S$ rested his hand on the panel between the buttons throughout the procedure. He was informed about the correctness of his response by a light (red or green) which appeared immediately. Then the next pair of colored words and required judgment were presented. Both the accuracy and latency of response were recorded.

Each of the 14 pairs was repeated three times during the procedure: once for each of the three questions. There were two random orders of the resulting 42 slides, and each $S$ participated in one of the orders, repeating it twice. Assignment to order was made randomly; 15 Ss were assigned to one order and 12 were assigned to the other. In addition, there were 21 pairs that were presented as pretraining material so that the $S$ would be thoroughly practiced in the procedure before beginning the experimental judgments and also so that a set would be established to respond as quickly as possible, but accurately.

RESULTS

Since the experimental conditions were represented by different numbers of responses, a mean was obtained from each S's correct responses for each experimental condition. These mean scores were used to represent the Ss' reaction times for the different experimental conditions.

There were few errors-fewer than three per $S$ during the experimental judgments. Incorrect responses were not included in the mean scores. Where errors occurred, the remaining correct responses were used to compute an S's mean score for an experimental condition. Fortunately, there were no cases in which a $S$ had no correct response for a given experimental condition.

The effect of the following variables on correct reaction times was assessed, using analysis of variance: order, word type (color name or object name), print color (same or different), and word (same or different). This is a mixed design with repeated measures on the last three variables (following Winer, 1962, pp. 319-337). A separate analysis of variance was computed for each of the three types of judgment-words, colors, or both. The order variable had no consistent effect on any of the judgments.

\section{Color Judgments}

The analysis of response times for correct judgments of print color revealed significant effects of word $[F(1 / 25)=7.14, p<.025]$ and of color $[F(1 / 25)=8.57, p<.01]$. When the two words of a pair were the same, judgment of print color was slower than when the words were different. However, when the print colors were the same, judgment of color was faster than when the print colors were different. In addition, the word and color variables interacted with the type of word judged: F Type by Word $(1 / 25)=6.25, \mathrm{p}<.025 ; \mathrm{F}$ Type by Color $(1 / 25)=4.44, p<.05$. (The degrees of freedom for error terms were calculated on the basis of the discussion of analysis of variance for unequal group size in Winer, 1962, pp. 374-378.) Tables 1 and 2, respectively, illustrate these two interactions. Newman-Keuls tests for multiple comparisons indicated that both of the main effects depended on the stimulus words being color names rather than object names. Matched 
Table 1

Mean RT in Seconds to Print Color as a Function of Word Type and Word Match

\begin{tabular}{lcc} 
& \multicolumn{2}{c}{ Type } \\
\cline { 2 - 3 } & $\begin{array}{c}\text { Object } \\
\text { Names }\end{array}$ & $\begin{array}{c}\text { Color } \\
\text { Names }\end{array}$ \\
\hline Words Match & .96 & 1.00 \\
Words Differ & .96 & .94 \\
\hline
\end{tabular}

Table 2

Mean RT in Seconds to Print Color as a Function of Word Type and Color Match

\begin{tabular}{lcc}
\hline & \multicolumn{2}{c}{ Type } \\
\cline { 2 - 3 } & $\begin{array}{c}\text { Object } \\
\text { Names }\end{array}$ & $\begin{array}{c}\text { Color } \\
\text { Names }\end{array}$ \\
\hline Colors Match & .95 & .92 \\
Colors Differ & .97 & $\mathbf{1 . 0 2}$ \\
\hline
\end{tabular}

words or differing print colors increased reaction time only when the words were color names.

\section{Word Judgments}

The analysis of response times for correct judgments of words revealed significant effects of each of the three main variables: type $[F(1 / 25)=5.00$, $\mathrm{p}<.05]$, word $[\mathrm{F}(1 / 25)=13.00$, $\mathrm{p}<.005]$, and color $[\mathrm{F}(1 / 25)=$ $15.00, \mathrm{p}<.001]$. Response times were shorter for object names than for color names. Response times also were shorter when the words matched than when they differed and when the print colors matched than when they differed.

Each of the three main variables also interacted with the others in affecting response time: $F$ Type by Word $(1 / 25)=4.38, \mathrm{p}<.05 ; \mathrm{F}$ Type by Color $(1 / 25)=5.38, p<.05$; and $F$ Word by Color $(1 / 25)=24.17$, $\mathrm{p}<.001$. Tables 3,4 , and 5, respectively, illustrate these three interactions. Newman-Keuls tests showed that response times were shorter for matched than for different words only when the words were object names (Table 3 ). Also, response times were longer in the presence of differing print colors only when the words were color names (Table 4). The Color by Word interaction indicated that response times for matched words were shorter when the print colors matched than when they differed (Table 5). If the words or print colors or both were different, reaction time increased.

\section{Both Judgments}

In this type of judgment, the $S$ was asked whether both the words and print colors were alike. The analysis of variance for correct reaction times for these judgments considered the variables of print color and word as one variable with four values since both aspects were relevant for making the judgments. The analysis of variance showed a significant effect of these aspects on response times $[\mathrm{F}(3 / 75)=17.37, \quad \mathrm{p}<.001)$. This effect is illustrated in Table 6. Newman-Keuls tests showed that response times were shorter when either both aspects matched or both differed than when one aspect matched and one did not.

\section{DISCUSSION}

The results can be summarized as reflecting two types of effects on response times; effects on "same" vs "different" judgments, and effects of the irrelevant aspect on judgments of the relevant aspect. The first type of effect is found in judgments of print color where color names produce lengthened judgments of different print colors (Table 2). This type of effect is found in judgments of words when object names (vs color names), and matching colors (vs different colors), facilitate judgments of matched words (Tables 3 and 5). Thus, color names interfere in judgments of both words and print color.

The second type of effect-that of the irrelevant dimension-are also found for all three types of judgment. Matched color names interfere with judgments of print color (Table 1), and color names written in different colored print interfere with judgments of words (Table 4). When both aspects are relevant, a mismatch on either one produces interference (Table 6).

It should be emphasized that the present experiment used only two colors and few pairs of words, and hence generalizations are tenuous. Nevertheless, a hypothesis can be suggested as the basis for future experiments: in a multidimensional task of this type, Ss try to process only the information necessary to arrive at the correct decision. For example, consider the effects illustrated in Table 5, wherein Ss are judging whether a pair of words is alike or different. The $S$ can check

Table 3

Mean RT in Seconds to Words as a Function of Word Type and Word Match

\begin{tabular}{lcc} 
& \multicolumn{2}{c}{ Type } \\
\cline { 2 - 3 } & $\begin{array}{l}\text { Object } \\
\text { Names }\end{array}$ & $\begin{array}{c}\text { Color } \\
\text { Names }\end{array}$ \\
\hline Words Match & .95 & 1.01 \\
Words Differ & 1.05 & 1.05 \\
\hline
\end{tabular}

Table 4

Mean RT in Seconds to Words as a Function of Word Type and Color Match

\begin{tabular}{lcc}
\hline & \multicolumn{2}{c}{ Type } \\
\cline { 2 - 3 } & $\begin{array}{c}\text { Object } \\
\text { Names }\end{array}$ & $\begin{array}{c}\text { Color } \\
\text { Names }\end{array}$ \\
\hline Colors Match & .99 & .99 \\
Colors Differ & 1.01 & 1.08 \\
\hline
\end{tabular}

Table 5

Mean RT in Seconds to Words as a Function of Word Match and Color Match

\begin{tabular}{lcc}
\hline & $\begin{array}{c}\text { Words } \\
\text { Match }\end{array}$ & $\begin{array}{l}\text { Words } \\
\text { Differ }\end{array}$ \\
\hline Colors Match & .92 & 1.06 \\
Colors Differ & 1.05 & 1.04 \\
\hline
\end{tabular}

Table 6

Mean RT in Seconds to Both Words and Colors as a Function of Word

Match and Color Match

\begin{tabular}{lcr}
\hline & $\begin{array}{r}\text { Words } \\
\text { Match }\end{array}$ & $\begin{array}{r}\text { Words } \\
\text { Differ }\end{array}$ \\
\hline Colors Match & .97 & 1.04 \\
Colors Differ & 1.10 & .92 \\
\hline
\end{tabular}

some shape-of-letter variable initially; if there is a match-and if the colors match-he can respond "same." Any difference that he detects, either in color or shape, requires him to read the words, thus slowing his reaction time for responding to the words as "same" or "different." Or consider the effects shown in Table 2, wherein print color is being judged. The $\mathrm{S}$ can check the colors for a match; if they do match, he responds quickly. If the colors do not match, he then proceeds to read the words; if the words happen to be color names, he then must sort out the semantic content of what he has read from the variable he is to judge, i.e., print color. Finally, consider the data illustrated in Table 6, wherein both aspects are relevant for the judgments. If both the letter shapes (perhaps initial letters) and colors are detected as different or if both are detected as matching, the $S$ can respond without further processing the stimulus material. If, however, the initial check shows one match, the $S$ then proceeds to read the words before responding.

The general hypothesis suggested-that the $S$ tries to process only the information that seems to be required for a correct decision-could be tested in a modified form of the present experiment. In one condition, Ss could be informed of their task (i.e., judgment of words, colors, or both), prior to presentation of the colored word pair. In this case, the $S$ ought to be able to "prepare" himself to check only the relevant variable(s), and the interference effects might disappear. In a second condition, the $\mathrm{S}$ might be informed of his task only after presentation of the pair of colored words, i.e., the words would appear and disappear from view before the $\mathrm{S}$ was told what to judge. In this case, he would presumably process the maximum information available-and the interfering effects of color names with print color ought to be more apparent. Such conditions 
were used with somewhat different types of stimulus material in a recent developmental study of visual selective attention (A. Pick, Christy, \& Frankel, in press). The results of that study showed that children process stimulus information differently, depending on whether or not they have knowledge of the relevant aspect prior to stimulus presentation.

It may be of interest to consider the relation between the results of this experiment and the traditional Stroop effect. The stimulus materials for this expriment were like those of a Stroop experiment, but the response required of the Ss was not. The task of a Stroop experiment requires $S s$ to name the print color of color names or of other items such as noncolor words, color patches, etc. The marked difficulty of performing this task when the print color is incongruous with the color names is known as the Stroop effect.

In many recent experiments, tasks other than naming have been used in order to identify the basis of interference of color names with responses to print color. The results of these experiments have shown that the degree to which color name produce difficulty in responding to incongruous print color depends on the S's task. Requirements of discriminating print color or counting colored words seem not to be hampered much by color names (Derks \& Calder, 1969; Egeth, Blecker, \& Kamlet, 1969). Such results support the hypothesis that the interference in the Stroop task occurs after the color names have been read (Dalrymple-Alford \& Azkoul, 1972), and that if the task does not require word reading and recognition, then there is not interference from incongruous color names (Murray, Mastronardi, \& Duncan, 1972). Separate tabulations were made of the response times in the present study for the print color of incongruously vs congruously colored color names. This comparison revealed no differences in response times dependent on the congruity of the print color-color name relation, thus lending additional support for the hypothesis that the Stroop effect depends on word reading and recognition.

The task of the present experiment did not vary with different conditions, but the stimulus aspect to be compared did. The $\mathrm{S}$ never had to read the words in order to arrive at a correct response. It is suggested that reading words was the fairly automatic "next stage" after checking colors and shapes. When words were read, interference occurred; when words were not read, print color-color name relations had no effect on response times. In general, it is argued that both task and stimulus features lead Ss to adopt one or another strategy of information processing.

\section{REFERENCES}

DALRYMPLE-ALFORD

AZKOUL, The locus of interference in the Stroop and related tasks. Perception \& Psychophysics, 1972, 11, 385-388.

DERKS, P. L., \& CALDER, E. S. Information processing and verbal labels: The Stroop color-word test. Paper presented at the meeting of the Eastern Psychological Association, Philadelphia, 1969.

EGETH, H, E. Selective attention. Psychological Bulletin, 1967, 67, 41-57. EGETH, H. E., BLECKER, D. L., \& KAMLET, A. S. Verbal interference in a perceptual comparison task. Perception \& Psychophysics, 1969, 6, 355-356.

MURRAY, D. J., MASTRONARDI, J., \& DUNCAN, S. Selective attention to "physical" vs "verbal" aspects of colored words. Psychonomic Science, 1972, 26, 305-307.

PICK, A. D., CHRISTY, M. D., \& FRANKEL, G. W. A developmental study of visual selective attention. Journal of Experimental Child Psychology, in press.

POSNER, M. I., \& MITCHELL, R. F. Chronometric analysis of classification. Psychological Review, 1967, 74, 392-409.

TREISMAN, A. M. Strategies and models of selective attention. Psychological Review, 1969, 76, 282-299.

WINER, B. J. Statistical principles in experimental design. New York: McGraw-Hill, 1962. 